\title{
Hashtags 2.0 - An Annotated History of the Hashtag and a Window to its Future
}

\section{Hashtags 2.0: breve historia y proyección de futuro}

- Guest paper -

Reception date: 8 June 2017

Published: 1 July 2017

To cite this article: Salazar, E. (2017): Hashtags 2.0 - An Annotated History of the Hashtag and a Window to its Future, Icono 14, volumen 15 (2), pp. 16-54. doi: 10.7195/ri14. v15i2.1091 


\section{MONOGRÁFICO}

\section{Abstract}

Hashtags are an example of a Folksonomy, a term coined by Van der Val in 2004 to designate any label (or "tag") that helps in the process of indexing and retrieval of online content. That said, the hash (\#) symbol has a long heritage throughout the computer age.

This paper makes an attempt to trace that history, since the hash was first used as a technology aid and towards its emergence as a new construct, the hashtag. It was first proposed openly by Chris Messina as simple means to "form groups" on Twitter, mirroring, in some ways, the way in which the \# symbol was used on IRC (Internet Relay Chat) to designate "channels" themselves associated to specific topics and content exchange. The San Diego bushfires of October 2007 lead to an organic growth in the adoption of hashtags, growth that has not stopped since, making them ubiquitous in the current Internet age.

Be as it may, the popularity of the hashtag made it also a vehicle to understand how information flows. Consequently, there is an incredibly rich literature explaining the mechanics of diffusion through social networks, opening, in the process, a new question: is that all for the hashtag? That's a question we also attempt to answer by introducing a new construct: the "programmable hashtag" (or p\#).

\section{Key Words}

Social Network - Hashtags - Programmable Hashtags - Information Era - Graph Theory 


\section{Resumen}

Los hashtags son un ejemplo de lo que se denomina Folcsonomía, termino acuñado por Van der Val en 2004 para designar aquellas etiquetas ("tag") que ayudan al proceso de indexación y búsqueda de contenidos online. Dicho esto, el simbolo almohadilla of "hash" (\#) posee una historia bastante rica a lo largo de la era de la computación.

Este artículo traza la rica historia de este símbolo desde su empleo como ayuda tecnológica hasta su reinvención como hashtag. Esta nueva iteración fue propuesta por Chris Messina para facilitar la creación de grupos en Twitter replicando, en cierto modo, el uso del simbolo \# en IRC (Internet Relay Chat) para designar "canales" que estaban asociados a tópicos específicos y el intercambio de información en torno a ellos. Los incendios que sacudieron San Diego en Octubre del 2007 incentivaron el crecimiento orgánico en la adopción del hashtag, crecimiento que no se ha detenido desde entonces, haciendo del mismo un simbolo casi ineludible en las comunicaciones actuales.

La popularidad del hashtag lo ha hecho también un vehículo para entender los flujos de información. Consecuentemente, se ha generado una literatura muy rica que intenta explicar los mecanismos de difusión en redes sociales, abriendo, al mismo tiempo, un nuevo interrogante: ¿es eso todo lo que puede ofrecer el hashtag? Este paper trata de dar respuesta a dicha pregunta introduciendo, en el proceso, un nuevo concepto, el de "hashtag programables" (o \#p).

\section{Palabras clave}

Redes Sociales - Hashtags - Hashtags Programables - Era de la Información - Teoría de Grafos 


\section{MONOGRÁFICO}

\section{Introduction}

Social networking has now become, for many, an integral part of their everyday life. Something taken almost for granted. It's estimated that roughly $37 \%$ of the world's population, or 2.8 billion people, actively engage in at least one social network. Technology has been a fundamental driver behind this phenomenon. This is readily reflected by the penetration of mobile platforms (e.g. about half the world's population use a smartphone nowadays, and $91 \%$ of people accessing a social network do so through them) and the spread of broadband.

Each social network has created a "preferred way" for interaction (so, for example, Instagram primary focus is image-sharing; Twitter leans more towards text messages; Facebook combines both) but in the past 10 years or so we have witnessed the surge in the adoption (or referencing, when not natively supported) of a specific information label, the hashtag. It's nothing more than a combination of characters led by the hash (\#) symbol, hence any combination of characters (in theory, whether or not they have a discernible meaning) preceded by a hash forms a hashtag. In practice, however, their function is to ease the task of finding messages having a specific theme or content. For the most part they are un-moderated (created by the users themselves) and when adopted by enough people within a social network they help attract more individuals to the content it references. Because of this very property, hashtags are considered to be an example of a Folksonomy (Muller-Prove, 2008). ${ }^{1}$

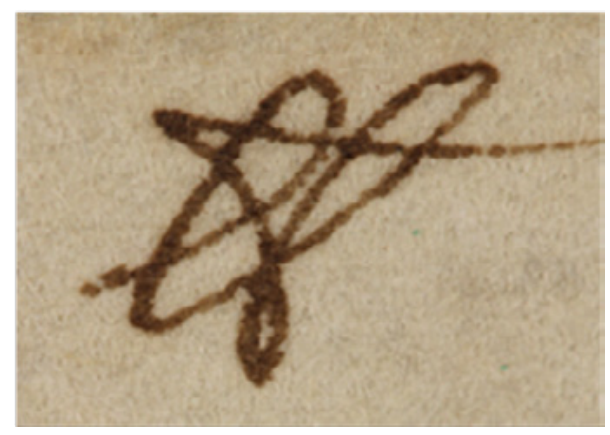

Figure 1: The abbreviation for libra (or "pound in weight") from the handwriting of Sir Isaac Newton. In Keith Houston, Shady Characters (2013, Fig. 3.1, pp. 41). Photo courtesy of the Roy G. Neville Historical Chemical Library, PA. 
To most people, hashtags are assumed to be a child of the new era spawn by social networking but this is not quite correct. In this paper I will attempt to illustrate the history behind this social construct and explain some of the features (from a technical standpoint) that make it so unique. At the same time, I will suggest the ways in which the functionality brought by the hashtag could be improved, presenting a new construct: the "programmable hashtag" (or p\#).

\section{Methodology}

The approach used in this paper has two strands. One follows a historical review of the use of the hash symbol in modern times, using a combination of sources ranging from material published in refereed journals to personal accounts by many of the actors in this play, compiled from blog entries and other relevant sources, including journalistic material. This provides a framework as told by those directly involved in the process leading to the birth of the hashtag.

The second strand is more focused on the hashtag as a means for both curating information and facilitating its diffusion through social networks. At this juncture we move towards an analysis based on the mathematics that help explain emerging patterns of community formation, virality and information diffusion beyond follower-followee interactions.

This helps us delineate the environment for the introduction of a new concept, that of "programmable hashtags" (abbreviated p\#). The $\mathrm{p \#}$ is a technology put recently into use and can be seen as a new form of marketing technology using social media as an amplification chamber. The major difference with the current options available for social media advertising is that the $\mathrm{p \#}$ does not rely on native social media formats but rather helps integrate traditional and digital advertising. $\mathrm{Be}$ as it may, the use of $\mathrm{p \#}$ is not restricted to advertising as any sort of content could be pushed through it, and we provide a description as to how that takes place.

Conclusions follow. 


\section{MONOGRÁFICO}

\section{The (incomplete?) modern history of the \#}

The role played by the \# character in communications can be traced back to 1964 and its baptism as "octotherp" by Howard Eby and Lauren Asplund, two engineers working for Bell Labs. The name came about as a sort-of joke on one colleague, Douglas Kerg. ${ }^{2}$

It sprung during "brainstorming at lunch" between Asplund and Eby, but the circumstances leading to it were seemingly less jocular. I'll leave that story for those feeling the need to know (Huston, 2013). In fact, some authors dispute this provenance for the name although everyone agrees it resulted from invention of the touch-tone keypad by AT\&T engineers, sought as a replacement for the rotary (pulse) dials which had been used for decades; by the way, Bell labs was the "research arm" of AT\&T (Koten, 1994; Carlsen, 1996).

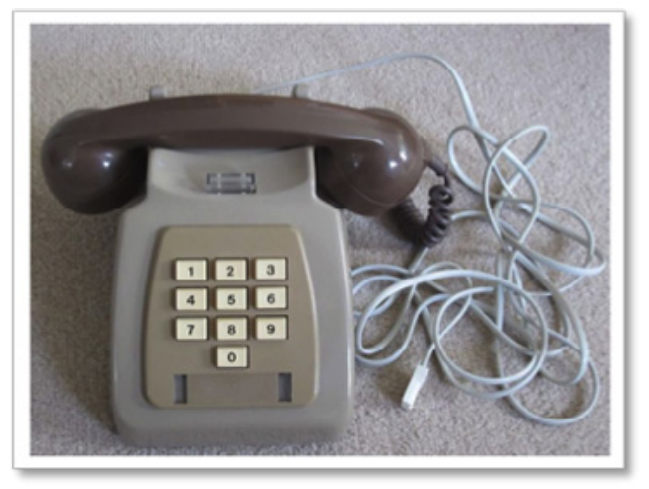

Figure 2: An early 10 key touch-tone phone.

The first touch-tone keypads had no "\#" (or "*") key in them. This is clearly seen in a video made by AT\&T (http://bit.ly/2s3tjsl) to promote the new technology on occasion of the 1963 World Fair in Seattle. This layout, however, proved to be controversial, accountants (accountants!) being the ones mostly complaining about it. ${ }^{3}$ Interestingly enough, the tested system had 12 different tone combinations but because there was no protocol at the time for the use of non-numeric characters the AT\&T brass (wary those new keys would confuse consumers) opted instead for the 10-key layout. 
Both the \# and * characters appeared later to provide special functions. It was, ultimately, a logical step. The big difference between the pulse and tone technologies is that a pulse can only travel as far as the exchange servicing the originating phone (rather than jump through the hoops) but a tone can cover the entire distance to the destination phone, thus opening the door to do "remote tasks" (such as controlling an answering machine at the other end). In the UK, special functions using the * and \# keys allow users on the BT network, for example, to set-up a call alarm by pressing * $55^{*}$ and then the desired ring time followed by a \#.

Fast-forward to the early-80s, the time when Bulletin Board Systems (BBS) became popular. During the pre-Internet age they provided people with a way to exchange information (and do many other things) using a computer, an analog modem and a phone line. ${ }^{4}$ In its beginnings BBSes became a local phenomenon, because users had to pay (then, quite expensive) long distance charges if connecting to a non-local BBS. Hence, besides using those boards for digital "interaction" (a precursor to what we now know as "online communities") there was also a lot of physical, personal contact between the people actively participating in them.

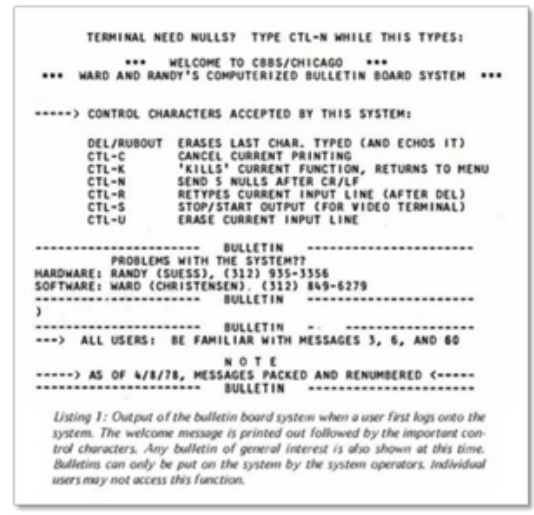

Figure 3: Typical BBS welcome screen

Some years later, it was the Internet Relay Chat (IRC) what opened the door for the reincarnation of the \#. Conceived as an "extension" to the BBS it was created during the summer of 1988 by Jarkko (aka "WiZ") 0ikarinen to replace a program called MUT (MultiUser Talk) on a BBS called OuluBox hosted at the University of Oulu, in Finland. ${ }^{6}$ 


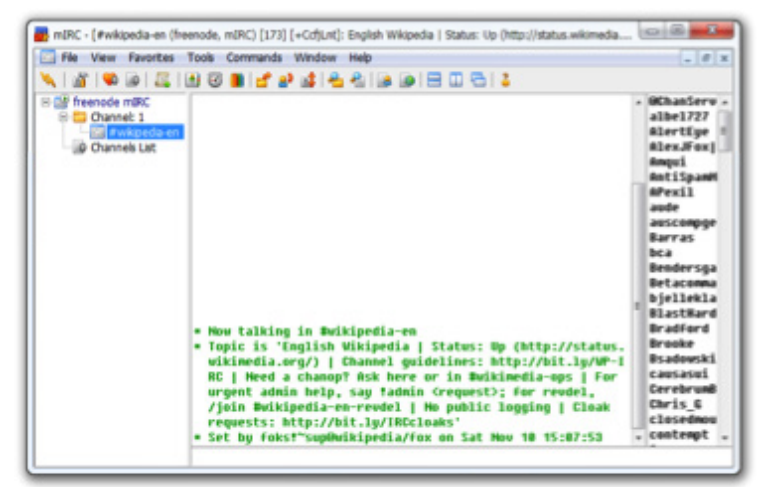

Figure 4: An IRC client welcome screen

The popularity of IRC, however, should perhaps be credited to Jyrki Kuoppala, then at Helsinki University of Technology. ${ }^{7}$ It was Kuoppala who convinced Oikarinen to persuade the folks at Oulu to make the IRC server source code (IRCd, the " $d$ " stands for "daemon") freely available, a request to which they eventually agreed.

That move quickly led to another IRC server becoming operational at Helsinki's Computer Science department and soon enough other universities followed in Finland, where it gained quick adoption.

By the end of 1989, IRC had already crossed the Atlantic and at that point it quickly spread throughout the Internet. ${ }^{8}$

What about the \# character? It was adopted on IRC as a means to identify a channel (so, e.g. you would type /join \#XYZ to join channel XYZ). That very simple role transformed the \# from an otherwise simple, convenient character into perhaps one of the first examples of a Folksonomy.

An interesting fact (and we'll see below the link to Twitter and the hashtag in particular) is that the surge in the use of IRC was prompted by the First Gulf War. ${ }^{9}$ During Iraq's invasion of Kuwait, information kept flowing through IRC using an Internet line into Kuwait that remained functional for about a week after radio and TV broadcasts ceased. Contrary to typical news-group methods (where content is authored at one point in time and then uploaded for others to read and respond to) IRC allowed users to link-up and communicate with each other in real-time. 
Two channels, +war and +peace, were most active Internet chat groups from the beginning to the end of the Gulf War; at any one time there were between 250 and 350 users logged on either channel. As pointed out by Robert Nideffer, "these folks were out at the bleeding edge of a technological fringe in a war that was enabled by, and discursively reproduced through, high-tech systems" (Nideffer, 1995). ${ }^{10}$

Some authors signal that episode as "the most widely cited instance of cross-cultural dialogue on IRC" (Rheingold, 2000) and a precursor of the role played by Twitter, many years later, during the Arab Spring events (Howard and Hussain 2011, 2013). ${ }^{11}$

From the early 2000s IRC usage has seen a steep decline both in number of users and channels, as people began to migrate to other platforms. Oikarinen attributes such shift to the increasing commercialisation of the Internet. He argued that "companies want to bring users to their walled gardens, to keep the users' profiles locked there and not make it easy for users to leave the garden and take their data with them."12

\section{The revival of the \#}

Fast-forward now to the modern era of social networking, 2007 to be more precise. By then, we had learned to love (or loathe, in equal measure) the likes of MySpace, Twitter, Facebook and other social networking platforms. Let's turn our focus to one of them, Twitter. ${ }^{13}$

It had only been around briefly, because the service was launched only the previous year and it had very limited functionality compared to today's Twitter service. Twitter invited users to answer a simple question ("What are you doing?") in the space of 140 characters. Such "economy of words" provided a rather efficient mechanism to let other users (in particular, your family and friends) know what was happening with or around you (Malik, 2006). ${ }^{14}$ 


\section{MONOGRÁFICO}

Few might nowadays remember there was another kid in town at the time, Dodgeball. There is an interesting article on Techcrunch comparing both platforms, on occasion of the 2007 South by Southwest (known as SXSW) event. Perhaps also worth mentioning that in mid-2004 the company behind Dodgeball (Ubiquity Labs LLC) signed a much talked-about marketing partnership with Absolut vodka, whereby the brand sponsored text messages in which Dodgeball recommended venues where people could meet up to have a drink (Cho, 2004)..$^{15}$

The \# appeared on Twitter over a year after the platform was launched. Proposed by a San Francisco-based technologist, Chris Messina (aka "Factory Joe") he made the idea known through his blog page and, of course, as a Tweet. \#barcamp became the first hashtag to appear on Twitter. ${ }^{16}$

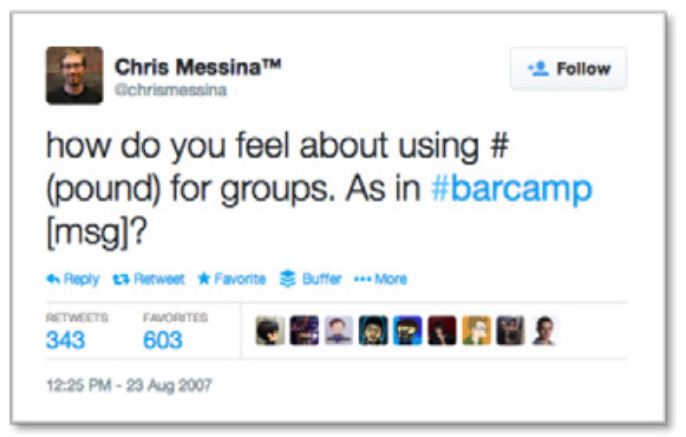

Figure 5: The first tweet suggesting the hashtag.

He thought of using the \# symbol as an ingredient for a system of "Tag Channels" (including subscription, following, muting and blocking) to make it easier for people to follow and contribute to conversations on topics of particular interest. Indeed, amongst the early Twitter community there was an idea floating around the formation of "user groups" (communities) on the basis of interests and relationships. For Messina, hashtags provided instead an effective means to create ad hoc channels, mirroring the way \#'s worked on IRC.

That explains why he suggested that hashtags should also incorporate a syntax. Such IRC heritage was clearly acknowledged by Messina, "[It] occurred to me that IRC presents a proven model for these needs [contextualization, content filtering 
and exploratory serendipity] with its foundation on channels, and so that's what I'm generally going to call them." (Italics mine.)

The discussion that followed in Messina's blog (a total of 87 comments) is quite interesting and revealing. For example, a commentary by Nicole Simon made the point that "Twitter is the nearest thing to what IRC was so good about - public communication" whilst Taylor@Taylorbeseda wrote "I'd hate to see Twitter turn into a rampant IRC chat room." Clearly, there was anything but uniformity of opinion and consequently the hashtag concept got a lukewarm reception by the Twitter community. ${ }^{17}$

It took about a month for things to start to change. Using his blog once again, Messina urged people to use the hashtag \#sandiegofire during the San Diego bushfires. ${ }^{18}$ His argument was that hashtags provided a "solid convention for coordinating ad-hoc groupings and giving people a way to organize their communications in a way that the tool (Twitter) does not currently afford." (Italics mine).

Twitter hashtags needed a bit more time to find their way in marketing. To my knowledge, the first such case involved Land Rover's controversial Twitter campaign by Wunderman on occasion of the 2009 New York Auto Show (Mullman, 2009).

The concept was to create a community Word of Mouth using a hashtag (promoted both on traditional media and online) to centralise the talk around the launch of their new models. The hashtag used for the occasion was \#LRNY (or "Land Rover New York" mimicking the famous ILNY acronym) and alongside the wave of PR that soon followed, it managed to raise some eyebrows (0strow, 2009). ${ }^{19}$ The strategy involved people tweeting "positive reviews" alongside the \#LRNY hashtag. Wunderman used the now-defunct Twittad (twittad.com) exchange, where Twitter users offered brands "timed access" to their accounts (to push advertising or for tweeting about a topic) for a fee, as a means for "seeding" the hashtag. Be as it may, it definitively opened a door. ${ }^{20}$ 


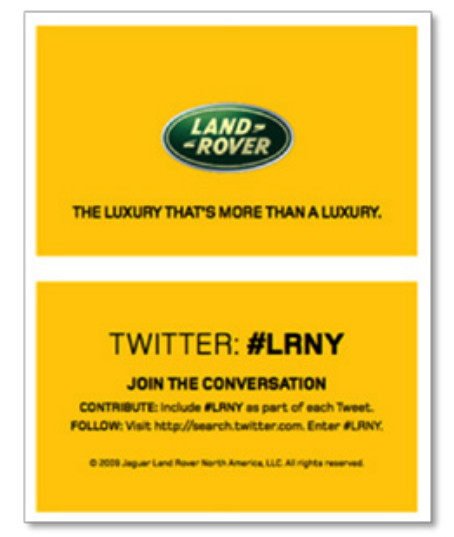

Figure 6: Wunderman's \#LRNY campaign.

In April, PepsiCo engaged in the first moderated hashtag conversation using \#PepTrends. ${ }^{21}$ On the occasion, 171 Twitter users took part. In the words of Bonin Bough, then PepsiCo's digital and Social Media guru:

The power of hashtags is that they open conversations up to potentially the entire Twitter community. They invite participation around a given topic from anyone and everyone (Bonin Bough and Agresta, 2001). ${ }^{22}$

By mid-April 2010 Twitter launched its first advertising platform to deliver "Promoted Tweets" opening to advertisers the possibility to push advertising directly into Twitter's stream (see http://bit.ly/2sTBW4D). Twitter's model hinged on advertisers bidding on keywords on a CPM (cost per thousand) basis but, at the same time, Twitter considered the adoption of a "resonance" metric based on how much a tweet was seen, favourited, re-tweeted or responded (in other words, create a score based on the multiple ways an user could interact with a tweet). ${ }^{23}$

So, Twitter's business model wasn't quite oriented towards monetising hashtags, in common with other platforms that attempted to position Twitter as an advertising medium (Tweetup springs to mind) although it didn't rule that out either. ${ }^{24}$ Case in point was Virgin America, one of launch partners selected by Twitter, which did so by creating the \#VXREDHOT promo code. ${ }^{25}$ 


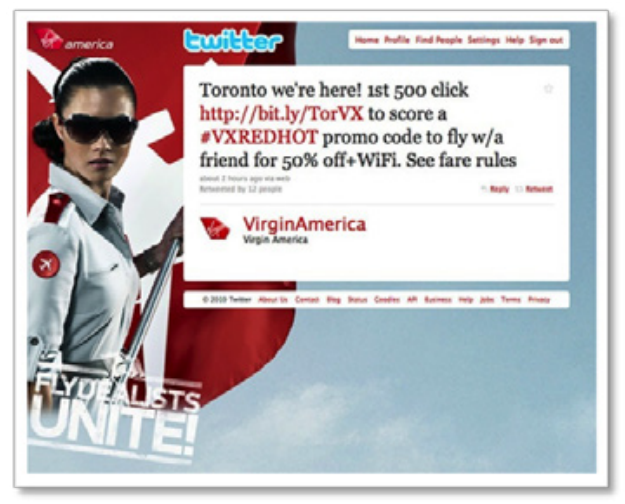

Figure 7: Virgin America's first Twitter campaign.

The rest is a rather predictable story. Hashtag-powered campaigns on Twitter eventually mushroomed, few becoming a success (such as \#0reoHorrorStories, which used Vine to create Oreo-themed parodies of some popular horror films) and many turning into a flop, when not an outright disaster (McDonald's and its \#McDStories is one such case).$^{26}$

\section{Search results for starbucks}

Save this search

Starbucks On 4/15 bring in a reusable tumbler and we'll fill it with brewed coffee for free. Let's all switch from paper cups.

http://bit.ly/9ZOP6N

about 8 hours ago via CoTweet by bradnelson

Promoted by Starbucks Coffee ta $100+$ Retweets

Figure 8: Another example of a marketing campaign on Twitter.

\section{What makes a \#tag "special" (if anything?)}

Be it on a push-button phone keypad, a channel identifier on IRC or given a new lease of life as a hashtag, the \# character presence has become the sign of our times. As we have argued, hashtags have helped people organise themselves when disaster struck, ${ }^{27}$ became the summons during episodes of social unrest, ${ }^{28}$ promoted the social good ${ }^{29}$ or simply became a way to share and generate "conversations" about mundane topics. 


\section{MONOGRÁFICO}

In essence, hashtags have kept communities "connected" (Howard, 2010). ${ }^{30}$

New hashtags constantly appear, some are rapidly forgotten but others become prominent through use and repetition. They are incredibly popular because they provide an efficient means for sorting and thematically selecting the mass of information that pours through social networks.

Bruns and Stieglitz have provided their own taxonomy of the hashtag (Bruns and Stieglitz, 2012).

- The ad hoc ones, resulting "in response to breaking news or other unforeseen events" that quickly spread as more Twitter users "see the hashtag in their Twitter feeds and begin to use it themselves" (also in Bruns and Burgess, 2011);

- The recurring ones, used by twitter users to repeatedly contribute (add into the discussion) around a certain topic (e.g., \#wikileaks); and

- The praeter hoc ones, predetermined (and encouraged) by certain organisations for users to adopt when tweeting about a particular event (e.g., backchannel hashtags such as \#TEDx and \#XFactor for the homonymous TV show).

In a separate paper, Bruns and Moe make a further distinction between "topical" and "nontopical" hashtags (Bruns and Moe, 2013).

- Topical hashtags, as the name suggests, are those used to contribute to a discussion on a particular topic. These could be also further divided into hashtags related to long-standing themes (\#wikileaks as noted above), backchannels to TV events or reactions to particular issues or events (e.g., \#royalwedding which, interestingly enough, seems at the time was a "sponsored" hashtag).

- Nontopical hashtags such as \#fail are basically "emotive markers" that are applied to any type of tweet. Although they have a communicative purpose, they are considered a deviation from the originally intended use of the hashtag. 
Rzeszotarski and co-workers proposed yet another sub-classification, the "Question and Answer [Q\&A] hashtags" or hashtags which flag questions for which users are seeking "various types of objective and subjective information" (Rzeszotarski, Spiro, Matias, Monroy-Hernández and Morris, 2014). They function "as a topical signifier (this tweet needs an answer!) and to reach out to those beyond [the user's] immediate followers (a community of helpful tweeters who monitor the hashtag)." In any case, topical and non-topical hashtags can be employed to signal the membership to a community or even the desire to belong to one (Yang, Sun, Zhang and Mei, 2012).

In essence, a hashtag is both text and metatext. ${ }^{31}$ It points to itself but at the same time points to any other information that becomes encapsulated by their contextual meaning. Therefore, hashtags provide a platform for debating events but they also become events themselves. In the words of Zappavigna, hashtags are "an emergent convention for labeling the topic of a micropost and a form of metadata incorporated into posts" (Zappavigna, 2012).

Twitter, more than in other social networking platform, make hashtags more intimately associated with the notion of "real time" (which is itself related to the issue of what's "trending" on Twitter). Tweets can appear into the readers' feeds out of chronological order, for multiple reasons: due to the location of the users, Internet traffic (a factor frequently related to location) or when users have asymmetric follower lists (Hoff, 2013)..$^{32}$ There is clearly nothing too "real" in the construction of time on Twitter, because as old tweets get replaced by new ones time passes at (probably) quite different rates for different people.

Be as it may, once strip to its bare bones, the marketing digiterati have been at work providing a number of reasons why hashtags have become a new currency:

- Hashtags seemingly improve clickthrough rates (CTR) on Twitter;

- Hashtags become links to search queries;

- Hashtags make someone (or something) get found by its target audience much easier; 


\section{MONOGRÁFICO}

- Hashtags provide a way to gain more followers; and

- Hashtags generate buzz.

(To avoid being repetitive I have omitted some of the reasons previously outlined.)

\section{So, where next?}

At this point, it seems there is not much left for a hashtag to do. There are, however, possibilities that could be open for this construct. But where? How?

Perhaps the best way to approach the challenge is by acknowledging that hashtags, despite inherently being a social construct, are inherently passive. If the change from being passive is to become active, the question is how could that be achieved?

One possible (not necessarily the only) answer is by transforming them into "programmable hashtags" or p\#.

\section{Hashtags and their context}

As we've previously discussed, hashtags have become ubiquitous in everyday conversation, matching the adoption of social networking platforms as the preferred mechanism for sharing information and experiences (otherwise known as "moments").

They provide the glue that connects people around the most diverse subjects. Why? Because hashtags enable a "specific syntax to indicate an intention to extend or narrow the range of addressees" (Bruns and Moe, 2013). In other words, hashtags greatly help to make topics, issues or events quickly discoverable by any user, beyond the follower-followee interactions that emerge and take shape in social networks. 
Clearly, those interactions are not necessarily reciprocal (two-way). In general, users in social networking sites (e.g., Twitter) can follow any user on the platform without the requirement of that other user to reciprocate. The connections between users in a social network can therefore have different meanings (Cheng, Romero, Meeder and Klienberg, 2011). ${ }^{33}$ By the same token, they are quite fluid because the conversations promoted through them frequently arise, become visible and disappear much faster than those happening within follower networks. ${ }^{34}$

Earlier we've stressed that hashtags are "both text and metatext" because not only point to themselves "[but simultaneously] point to any other information that becomes encapsulated by their contextual meaning" hence, one could argue, they should be a useful vehicle for understanding how social relationships and interests are intertwined..$^{35}$ Indeed, early research on collaborative tagging ${ }^{36}$ has shown that friends have a greater similarity (overlap) in vocabulary usage relative to a baseline of users picked at random (Marlow, Naaman, Boyd and Davis, 2006). Shifanella and co-workers have found that

[The] local alignment of users' tag vocabularies is clearly visible between nearby users in the social network, even for social tagging systems that lack a notion of globally shared tag vocabulary, such as Flickr. (Schifanella, Barrat, Cattuto, Markines and Menczer, 2006)

The proponents of social marketing techniques (Richardson and Domingos, 2002; Tsur and Rappoport, 2012) ${ }^{37}$ place a great emphasis on the number of connections between users or "density" of a social network as an indicator of how far, fast and deep information spreads from person to person. ${ }^{38}$ Indeed, it's not surprising to see why the popularity of a hashtag (how it "propagates" through a social network) depends on the relationships between the users first adopting it. However, the topicality of a hashtag also conveys information about the network structure around its users. ${ }^{39}$ People do show a degree of closeness on the basis of shared interests or goals, so if a hashtag "encapsulates" certain contextual meaning then specific network structures would emerge between users who become associated to such hashtag. 


\section{MONOGRÁFICO}

If there is a close connection between hashtag adoption and the topology of the connections among users in a social network, an important question to elucidate is whether that link is monotonic..$^{40}$ Intuitively the answer would be "yes", meaning that if the social graph of any user adopting (or creating) a hashtag is "dense" the expectation is that it would become more popular..$^{41}$ The contagion approach rests on this principle: people find about a hashtag from each other and it finds an increasing adoption (cascades) within their community..$^{42}$ But, strangely enough, there is also another pathway to popularity, located on the antipodes of virality.

The use of hashtags in social networks does not necessarily need to follow their "discovery" by users through their connections; in other words, a user does not need to have many connections (edges in the subgraph, or community, they belong to) for massive adoption. Take, for example, the hashtags that frequently emerge as a consequence of relevant events taking place in real life (e.g., the Arab Spring that I've mentioned earlier, the Ferguson riots or the Sao Paulo revolts). First-adoption users might belong to relatively small, coherent but otherwise unconnected (non-overlapping) communities, hence usage (in terms of number of hashtag adopters, not necessarily speed: I'll come to this in a moment) would be constrained by the size of those individual communities. However, if there is a large initial set of users of a hashtag (say, the first people that learn about an event) it could quickly become popular irrespective of the density of the subgraph they sit in.

This is the other plausible mechanism besides virality explaining how and why hashtags could become widely adopted.

Information flows on social networks usually take two forms. On Twitter, for example, users can follow other users and read their tweets without any approval but also can propagate information to their followers by re-tweeting. ${ }^{43}$ Interestingly enough, one would reasonably expect the probability of a retweet not to depend on the spread of a hashtag: in general, users do not "actively look" for tweets to retweet. ${ }^{44}$

I mentioned above the issue of "speed": small communities tend, by their own nature, to be more cohesive. ${ }^{45}$ In a social network environment, pretty much as in 
the real world, cohesiveness stems from like-minded individuals sharing common goals, interests, habits or preferences (Lim and Datta, 2013). ${ }^{46}$ This can be also understood in terms of the reachability among the nodes in a subgraph. ${ }^{47}$ If those subgraphs happen to map tightly knit communities, information tends to travel faster than otherwise because of the intrinsically shorter path lengths between the users in them..$^{48}$ So, once again, the question is whether the popularity of a hashtag is conditional on the number of edges in the initial subgraph(s).

To sum-up, the second scenario is one where popularity is induced by several locally dense communities. Here, locality is introduced as a property of cohesiveness: that of being invariant to changes in the (social) network outside of the community. ${ }^{49}$

Perhaps, at this stage, it's worth mentioning one of the properties that have been proposed to separate social networks (e.g. acquaintances or collaboration) from others (such as biological or technical networks) known as "assortative mixing": when neighbours of nodes with high degree ${ }^{50}$ also have a high degree and neighbours of nodes with low degree also have a low degree. ${ }^{51}$ The available data, however, suggests the case for assortative mixing (as characteristic feature) in social networks is not conclusive. Some studies have shown assortativity to be negative, in other words, users tend to connect to others with different degree to their own..$^{52}$ Others have reached conflicting results (Myers, Sharma, Gupta and Lin, 2014) once you factor in reciprocity, noting that every platform displays features which are part informational and part social.

For example, Twitter introduced to much fanfare its "Moments" feature (formerly known as "Project Lightning") offering users curated news, in real time, through their timeline. But there is also Facebook's "Instant Articles" feature, launched in conjunction with some major publishers, or Instagram's own notification feature, called "Explore". (In passing, let's not forget two things: firstly, that Facebook owns Instagram; secondly, that Facebook is now driving more traffic to news sites than Google itself.) The new kid in the block, Snapchat, has also joined the fray through its "Discover" feature unveiled in mid-January 2015, so effectively months before Instant Articles and scooping quite good press. ${ }^{53}$ 


\section{MONOGRÁFICO}

There are other complications, such as the fact that assortativity is also time dependent, meaning that (reciprocal) interactions between users in a social network often cluster around "common themes" that are mediated by specific events, which themselves have a timeline. ${ }^{54}$

One might might also ask, so what? Fact is, assortativity is one of the building stones towards understanding the mechanisms of social influence in communities, particularly in situations where social ties might not be mediated by (prior or current) physical contact.

Degree assortativity, however, is one of the possible forms of assortativity that have been explored in the literature; it is sometimes difficult to grasp why users in a social network are assortatively mixing with respect to specific dimensions and not in others..$^{55}$ Being that the case, the question becomes whether hashtags "embodiment" play an equivalent role to sentiment, and there are good reasons to support that view. ${ }^{56}$

\section{Quick takeaways}

The discussion above highlights a number of potentially interesting facts. ${ }^{57}$

- Virality is not of the essence (and in some instances, perhaps not the fundamental mechanism at play) for a hashtag to become popular in a social network platform, as long as the hashtag has emerged and is driven by a public event with a massive audience. It could spread through users embedded in small, cohesive but otherwise unconnected communities ("locally dense" as we described earlier).

- Hashtags, on the other hand, could operate as a precursor of (non-degree) assortative mixing. However, it would happen as a second order effect, once a hashtag has reached a certain level of adoption and would be time dependent (as long as the hashtag remains popular).

From a marketing perspective, both features lead to some interesting possibilities and debunk some myths. 
- Firstly, let's reflect on the "power" of social marketing as we know it, or has been sold to us. The first observation is that native social advertising formats do not offer, by design, any particular advantages when compared to traditional advertising even among audiences which have a greater natural affinity to digital in general (e.g. the endlessly talked-about "millennials" or those belonging to "generation Z") and to social networking in particular.

- Advertising is an intervention, an event taking place at a certain point in time. Provided a campaign has "enough" reach ${ }^{58}$ the "eyes and ears" seeing or hearing those adverts could mean enough seeds are sown (sharing or commenting) in social networking platforms for the content to be known, ${ }^{59}$ and potentially also be further shared and commented by people who have not directly seen the advertising but might tempted to act upon it. This effect goes by the name of "reach amplification" and reflects the incremental (or net) contribution that social networking platform(s) could offer to brands.

- So, assuming that traditional media channels provide enough reach, people propagating such content though social networks need not to be connected beyond a community of users "local" to them to make it popular.

- However, for adverts to become amplified in a social network they would likely need to be mediated by another intervention: hashtags are one such possibility. ${ }^{60}$

- Hashtags could either be created by the audience(s) exposed to (and induced by) the advertising or themselves be a deliberate component of the communications campaign, the latter being the most frequent route.

- Hashtags could also induce (non-degree) assortativity that should help further amplify a brand's message. ${ }^{61}$

Therefore, rather than talking about "social media marketing" it's more appropriate to think about using social networks for marketing which is a slightly 


\section{MONOGRÁFICO}

different idea. It emphasises the proactive use that marketers could make of social networks' capillarity but at the same time it brings attention to the fact that it's not about native social media formats (such as Twitter's recent and much hyped "conversational ads") but traditional media and how you could make that content reverberate in the digital space.

I can hear some rumbling in the background about the benefits pouring from the digital data trove, particularly in relation to campaign targeting and the razor-sharp precision available through careful mining of digital footprints. That's the message advocates of native digital advertising formats try to hammer on. However, presently there is less to it than meets the eye ${ }^{62}$ and there are reasons why that might not be a sensible idea after all. ${ }^{63}$

\section{The future? From the \#-tag to the $\mathrm{p} \#$}

So here we are now, several years since hashtags have become a ubiquitous feature in social networking. It has somewhat distanced itself from the original ideas on how tagging (as a means for easy referencing and cross-indexing) was thought could (or should?) be applied to life-streaming platforms following the use of tags in other popular online services, such as Flickr or del.icio.us. ${ }^{64}$

Interestingly enough, there was an interesting debate going on the time (early to mid-2007, about a year following Twitter's birth) about the advantages of having group-like structures on Twitter. One example at that time was Jaiku's implementation, a (now defunct) social media, micro-blogging and life-streaming network that also came to life in Finland. The platform was acquired by Google in 2009.

As traditionally implemented, however, online groups were also perceived as rather heavyweight in terms of management, language syntax, usage conventions (which frequently implied a steep learning curve) and lacking flexibility so inherently being a rather unfriendly construct for a society seen, in the near future, to be decisively migrating towards the adoption of mobile applications beyond e-mail and SMS. ${ }^{65}$ Channel tags were therefore considered a better option by many. ${ }^{66}$ 
Be as it may, the idea eventually mutated into what a hashtag currently is. But, is that it?

I believe there is some room for improvements, so here I want to introduce the concept of "programmable hashtags". What are they?

The original idea originated from factual evidence that was also picked-up by UK consultants Rose McGrory as to the reasons explaining users' interaction with brands in the social media space. ${ }^{67}$

- A hefty $68 \%$ simply wants to "receive offers or competitions" from brands;

- Also 68\% look as Twitter for ways "to keep up to date with the latest news about them" (who knows, but perhaps "latest news" is cofounded with product "offers and competitions"); and

- $63 \%$ simply hopes to "receive more information related to [their] personal interests

In comparative terms, only $34 \%$ said to engage with brands "as a mark of their interest or loyalty" and $24 \%$ because "they like their content."

It clearly emerges those reasons have nothing to do with Twitter users eagerness to have "conversations" with brands, or to "co-create" or foster "authentic relationships" based on some form of "love" for them, or wishing to interact and "support themselves" through them, or any variations thereof. One has to look at Havas' Media "Meaningful Brands" yearly study for a simple fact that debunks much of the "people are in love with brands" nonsense: one of the headlines from their 2015 report reads "[most] people do not care if $74 \%$ of brands disappeared" (Italics mine) but that's nothing new. Back in 2013 they also found the "disconnect between brands and people continues with the majority of people still not caring if over $73 \%$ of brands ceased to exist" (Italics mine). ${ }^{68}$ 


\section{MONOGRÁFICO}

So, from a marketing perspective and taking on board the bulk of research on how (and why) people interact on social networks, plus the likely diffusion process of information passing through them, finding a mechanism that would tie hashtags to specific outputs became appealing. In addition, the aim was to avoid creating yet another social media native advertising format to adapting an already widely-accepted vehicle (the hashtag) to facilitate brands make the most of social networks' capillarity, helping them expand the reach of their advertising through traditional media channels. ${ }^{69}$ To reiterate: it's not about social media marketing but about using social networks for marketing.

Looking at what people seem to demand from their interactions with brands on social networks, hashtags could be used, for example, to deliver (rather than simply facilitate the knowledge of) incentives or links to pertinent content. The output: a discount coupon or a video, respectively. I have therefore labeled this

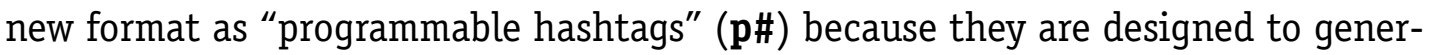
ate a (mediated but automatic) response once they are posted by a user of a social networking platform natively supporting this tagging method. ${ }^{70}$

The sequence is more or less as follows:

- A brand chooses to offer an incentive and they create a hashtag that (in its wording) encapsulates what the incentive is about.

- The hashtag needs to be advertised in order for it to be seen. There is no need for that to happen just through social media; in fact, traditional media channels might prove to be a much better option. I'l come back in a moment to the ripple effects once the $\mathrm{p \#}$ is "seeded" (picking-up on the earlier discussion).

- If the incentive involves a discount coupon, say, the hashtag would be used as the means for the delivery mechanism of that incentive.

- It means the hashtag is "programmed" to generate an outcome: if someone posts it, then it triggers an action, that action being the delivery of the incentive to anyone that has posted the hashtag. 
- As with any ordinary hashtag, it has to be "created" and what it triggers (when posted on a social network) should be decided beforehand. It's a mediated response because there needs to be an intermediation layer between the social network and the user for the incentive to be delivered. That's simply because there is no social networking platform out there that transfers (programmatically) certain user information to third party applications, for obvious privacy reasons, nor is the $\mathbf{p \# ~ p a r t ~ o f ~ t h e ~ i n s t r u c t i o n ~ s e t ~ o f ~ a n y ~ s o c i a l ~ n e t w o r k ~ t o ~ d a t e . ~}$

- Therefore, anyone posting a $\mathrm{p \#} \mathrm{linked} \mathrm{to} \mathrm{an} \mathrm{incentive} \mathrm{should} \mathrm{go} \mathrm{to} \mathrm{a} \mathrm{site} \mathrm{other}$ than the originating social network to register their interest and provide some basic information for the incentive to be delivered (crucially, a valid e-mail address).

- Such site, however, can be fully branded (in the same way microsites are designed) in order to provide a cohesive experience to the user.

- Once registered, the intermediation platform sends by e-mail the incentive in a suitable format (e.g. discount coupon, competition entry, admission ticket or content) to the poster.

\section{The ripple effect : how the p\# helps amplify the reach of an advertising campaign?}

At the beginning of this paper I've outlined the likely mechanisms for a hashtag (or a $\mathbf{p \# ~ f o r ~ t h a t ~ m a t t e r ) ~ t o ~ p r o p a g a t e ~ t h r o u g h ~ a ~ s o c i a l ~ n e t w o r k . ~ C o n t a g i o n ~ ( t h e ~ v i r a l ~}$ effect most people talk about) is one of them but I've also mentioned local network effects as a potential avenue for hashtag popularity. In Twitter, for example, the latter requires many users to become aware of and tweet the p\#: diffusion is local (within a relatively tight boundary of followers of those users tweeting it) but very many of those events lead to an amplification effect that could be equivalent to contagion along a dense network of users. How that could be achieved? Simply by advertising the $\mathrm{p \#}$ using media channels that guarantee it has enough visibility among the audience being targeted. That's unlikely to happen if a hashtag is promoted solely using a native social media (or digital) advertising format. 


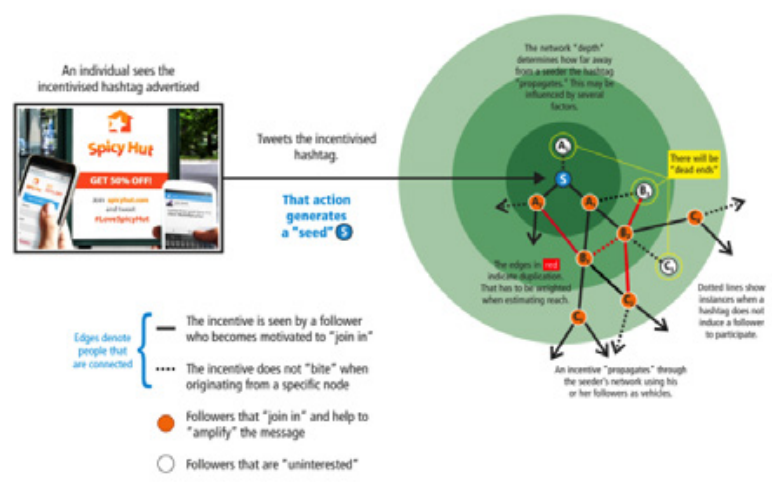

Figure 9: The mechanics of hashtag diffusion.

In addition, a p\# would inherit the characteristics of the audience targeted outside the social network(s) it's "seeded" into, becoming "self selecting" once it starts to propagate inside the network(s). There might be, of course, spillover effects taking place both outside and inside those social network(s); consequently, quite likely those seeds won't travel too far either from the "entry" point (when the initial $\mathbf{p \# ~}$ adopter $^{71}$ does not fall within the intended target audience) or once inside the network (should it reach a user that despite adopting it, does not belong to the target audience). They are potential dead-ends any informational cascade could eventually hit.

As I mentioned earlier, amplification refers to adoption by members of a social network not directly exposed to the advertising that promotes a p\# at the time they adopt it. That would happen if the intended audience, as a result, gets something that's meaningful to them. ${ }^{72}$ The $\mathbf{p} \#$ has been designed to precisely facilitate that process.

\section{Conclusions}

In this paper I have looked at the past, present and provided some hints as to the future of the (now widely used) hashtag. I hypothesise that a variation of the hashtag, the "programmable hashtag", could provide an interesting avenue to marketers struggling to use social networks in any meaningful way. 
Should the $\mathrm{p \#}$ be understood as yet another social media marketing tool? No. The $\mathbf{p \# ~ c o n c e p t ~ i s ~ s u p p o r t e d ~ o n ~ t h e ~ b e l i e f ~ t h a t ~ n a t i v e ~ s o c i a l ~ m e d i a ~ m a r k e t i n g ~ t o o l s ~}$ are mostly ineffective ${ }^{73}$ but a mechanism to help bridge the gap between traditional advertising and social media might be otherwise quite useful to brands.

The $\mathrm{p \#} \mathrm{concept} \mathrm{is} \mathrm{aimed} \mathrm{at} \mathrm{brands} \mathrm{that} \mathrm{recognise} \mathrm{what} \mathrm{people} \mathrm{say} \mathrm{they} \mathrm{want} \mathrm{(or}$ expect) from them in the social networking space. The additional advantage is that it could work across most social networks platforms supporting hashtags, therefore allowing $\mathbf{p \# ~ s u p p o r t e d ~ c a m p a i g n s ~ t o ~ r e a c h ~ a ~ f a i r l y ~ w i d e ~ a u d i e n c e . ~}$

\section{Notes}

This section provides additional information and references (complementing the main text) that might be of interest to the reader. Links are also provided to relevant material when available. Unfortunately, due to the dynamic nature of the Internet some of those links might become obsolete at the time of publication. Hence, feedback will be greatly appreciated in such cases.

[1] A Folksonomy is basically a keyword (or tag) that is freely selected and attached to any information resource, "the electronic equivalent of Post-It notes." The term Folksonomy (a portmanteau of the words folk and taxonomy) was coined in 2004 by Thomas Vander Wal. His own account can be retrieved from http://bit.ly/2qX4LNj.

[2] Kerg was the folk responsible for introducing the \# character in the American Standard Code for Information Exchange (ASCII for the masses).

[3] Keith Huston (2013), pp. 47.

[4] The first publicly known BBS (CBBS, the "C" standing for "Computerized") was developed by Ward Christensen and Randy Suess in 1978 (Christensen, ward and Suess, 1978). Of course, IRC (or BBSes in general) were not the only platforms that offered comparable services. But we're focusing on the IRC due to its specific use of the \#.

[5] It is interesting to note that "Get Together" events became a common feature of BBSes, where users had the opportunity to meet face to face.

[6] In the words of Oikarinen, "[T] he purpose was to allow USENET News-kind of discussion and groups there in addition to real time discussions and other BBS related stuff." For a link to Jarkko's own account, see http://bit.ly/2sEoYZe.

[7] He wrote the "rmsg" program for person-to-person communication, one of Oikarinen's "sources of inspiration" leading to his coding of IRC. 


\section{MONOGRÁFICO}

[8] In the UK, for example, although in 1992 Pipex opened-up the Internet to anyone with a home computer (until then, Internet was accessible mostly to users in JANET, the UK universities network) it was Demon who first ran IRC servers both on EFnet and IRCnet from 1993, when it was soon "found" by subscribers to the service.

[9] It should be said that IRC also played a role in disseminating news of the 1991 Soviet coup throughout the media blackout.

[10] Those interested can read those IRC exchanges from the logs available from the following links: http://bit.ly/2rBQCrw (Gulf War) or http://bit.ly/2sEGNYq (Soviet coup).

[11] See Lim (2012); Papacharissi and Maria de Fatima Oliveira (2012) or Douai (2013).

For a more general perspective, see Parmalee and Bichard (2012).

[12] However, the decline of IRC is perhaps best explained by a series of factors, according to Christian Lederer (aka "phrozen 77," the webmaster of IRC-junkie.org). Those are (a) a surge in DDoS (Distributed Denial of Service) attacks in the early 2000s that crippled the chat experience for loads of users; (b) the emergence of P2P (peer to peer) networks that made the distribution of illegal software easier than on IRC (incidentally, one of the two main reasons why people joined IRC in the first place, the other one being -you bet- porn); (c) the decreasing costs of cheap and reliable hosting, that facilitated migration to those who disagreed with the way a particular network was being run (taking with them the channel they operated and its followers); lastly, (d) the emergence of social networking platforms that made it easier (and more visually engaging) for people to communicate than through IRC.

[13] Many of the developments in the Twitter platform that cemented its role in public communications (e.g. cross-referencing using @reply format, integration of media uploads and hashtags) were user-led innovations.

[14] Comparing Twitter's adoption statistics to those of IRC during their initial years in existence, Twitter was a far greater. Estimates suggest an average of roughly 6,000 Tweets/day a year after that famous first tweet (https://twitter.com/jack/status/29) increasing to an average of about 400,000 Tweets/day on its second year and 3 million Tweets on its third anniversary.

[15] Clearly then, as now, brands keep persistently looking "for a variety of ways to reach [their] consumers" (in the words of Lorne Fisher, Absolut's spokesman). Google perhaps thought the same when they acquired Ubiquity Labs in 2005, only to shut it down in 2009.

[16] The article can be retrieved from http://bit.ly/2rWaoOP. In 2014, Messina spoke to the BBC about his "original" idea; see http://www.bbc.com/news/technology-30340622. Interestingly enough, the germ of (what would become) the hashtag can be traced back to a blog comment by Stowe Boyd a year earlier, "Carfi and Barnett on Support Tag Beacons" (October 19, 2006). See http://bit.ly/2rBZ1vb. Recently, answering to a query in Quora as to why the hashtag "idea" was not patented (besides the legal reasons why that would have been impossible) Messina himself answered that "[the] value and satisfaction I derive from seeing my funny little hack used as widely as it is today is valuable enough for me to be relieved that I had the foresight not to try to lock down this stupidly simple but effective idea." (underline mine) 
[17] For example, see this comment on the Twitter timeline http://bit.ly/2s4WgUB, the blog entry by Ontario Emperor, "Hashtag Challenges When Events Occur at Different Times in Different Locations" (January 1, 2008; link http://bit.ly/2s5bdG7) or "Why I Unfollow People Who Use Hashtags on Twitter" by another blogger, Dave Coustan (February 26, 2008; link http://bit.ly/2s4w5ND). In fact, Twitter executives themselves though the idea was unfeasible. Despite some mishaps along the way, some people were more receptive to the idea, such as Colby Palmer's "Tracking vs. \#Hashtags" (October 1, 2007; see http://bit.ly/ 2sEahFL) or Stephanie's Booth in her "Twitter Hashtags: A Quickie" (October 2, 2007; link http://bit.ly/2rC7MoV) and "Hashtags for my Followees" (December 18, 2007; see http:// bit.ly/2rMmnN3).

[18] See "Twitter hashtags for emergency coordination and disaster relief" (entry in Messina's blog dated 0ctober 22, 2007; link http://bit.ly/2r6vNRv). It was however a web developer, Nate Ritter, the first to use Twitter for reporting the event, although at first not employing a hashtag (prompting Messina to say those posts lacked "any kind of uniformity"); eventually, Ritter began to use the \#sandiegofire hashtag. He later recalled the experience in his blog piece "Using Twitter to Help Communities" (January 9, 2008; see http://bit.ly/2s4Gkl4) and in an in-

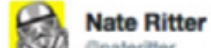

$\geq$ Follow

\#sandiegofire 300,000 people evacuated in San Diego county now.

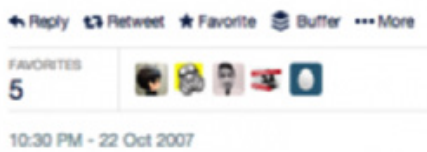
terview with NetSquared shortly afterwards (January 18, 2008; link http://bit.ly/2rBWqRI). Some commentators, however, think Michael Calore deserves the ultimate credit for making hashtags a "feature" in Twitter (although he never mentions it!) following his column in the Wired.com blog (Calore, 2007); it has since seemingly disappeared from Wired. Calore wrote at the time "here's an excellent real-world example [by Ritter] of the usefulness of Twitter's limited scope and feature set - Reporting breaking news quickly. They're certainly filing updates more frequently than most mainstream media outlets." (underline mine.) It was followed by an article going more "to the point" by Ryan Singel (2007); again, no mention of the \#sandiegofire hashtag although Ritter had been using it since 4:04 PM on 0ctober 22 .

[19] Besides the discussion about the use of what Adam 0strow defined as "sponsored hashtags" (0strow, 2009) and a hilarious blog commentary by Richard Stacy, "\#LRNY - I am an 'assclown' and a stalker!" (May 21, 2009). Link is http://bit.ly/2r2Tv62.

[20] Interestingly enough, it wasn't the first time companies looked at Twitter for marketing. When Messina pushed the hashtag idea, there was a German/UK company by the name Magpie (Be-A-Magpie.com) that offered to pay Twitter users for the insertion of adverts into their timelines (at a rate of one advert per five tweets). See the discussion by Mark "RIZZN" Hopkins in Mashable, "Magpie: Make Money on Twitter" (October 31, 2008; see http:// on.mash.to/2qX1mxF). Those interested in looking at Magpie's original website should look at the snapshots stored by The Internet Wayback Machine (the company was acquired by IZEA in mid-2011; see http://bit.ly/2sTUNwq). 
MONOGRÁFICO

[21] See http://bit.ly/2r6zFSm. Also, Mel DePaoli's blog “Beyond \#PepTrends with Bonin Bough of Pepsi Co \& Marian Salzman of Porter Novelli." (date unknown.) Link is http://bit. ly/2r6zNk0.

[22] Some might remember Bonin Bough as the folk that spearheaded PepsiCo's "digital fitness" boot camps; link is https://youtu.be/uEzaqQatIdQ. He perceived societies moving into digital at a (much) faster speed than most organisations, so "there's a gap, and [Pepsi sees the need] to work relentlessly to close that gap. We've looked for a way to describe it, and that's fitness. You can't just work out once." Embracing this new paradigm, Pepsi decided to launch in 2009 its much talked-about Refresh Project (see http://bit.ly/2sTX2QE) which judging by its results wasn't Pepsi's finest hour (see http://bit.ly/2bU1jv9). Bonin Bough left PepsiCo in 2012 as Pepsi decided to abandon the whole idea.

[23] For those interested, see the discussion by Brian Solis in http://bit.ly/2r6xD4X.

[24] A study by Crimson Hexagon (see http://bit.ly/2rBM4RJ) revealed that $42 \%$ of the Tweets that discussed "Promoted Tweets" revealed some concern they would turn to be nothing more than spam, against $21 \%$ who thought it was a sensible way to incorporate advertising into the Twittersphere .

[25] The promo involved a 50\% off promotion for the first 500 travellers that booked flights from Los Angeles or San Francisco (to prop-up the launch of their round-trip service between California and Toronto) using the code \#VXREDHOT. It sold out in just three hours (making it Virgin America's fifth highest day in sales ever) adding roughly 12,000 Twitter followers in the process. Besides Virgin America, the other launch clients selected by Twitter were Bravo and Starbucks.

[26] On the day \#McDStories was launched (January 18, 2012) it generated 13,072 negative tweets and just 2,829 positive tweets.

[27] There are many examples of comparable applications of the hashtag since the San Diego bushfires. For a perspective on Twitter's use during the Japanese Tsunami of March 2011, see (Acar and Muraki, 2011). See also the paper by Kate Starbird and Leysa Palen (2010) or Carrie Brown (2012); see also Carrie's blog entry on the project from the link http://bit.ly/2r6tKgl.

[28] The Arab Spring became a spark that ignited the massive adoption of hashtags as a means to reference and curate news around what was happening on the ground. Other comparable uses of the hashtag (by no means this is meant to be an exhaustive list) were \#VenPraRua ("come to the streets") on occasion of the protests triggered by the increase of bus fares in Sao Paulo during the 2013 Confederations Cup in Brazil (paradoxically, a slogan scooped from an Ad by Fiat in Brazil); \#JeSuisCharlie after the terrorist attack at the offices of the satirical magazine Charlie Hebdo in Paris (a slogan that also led to some controversy); \#0ccupyGezi during the protests triggered

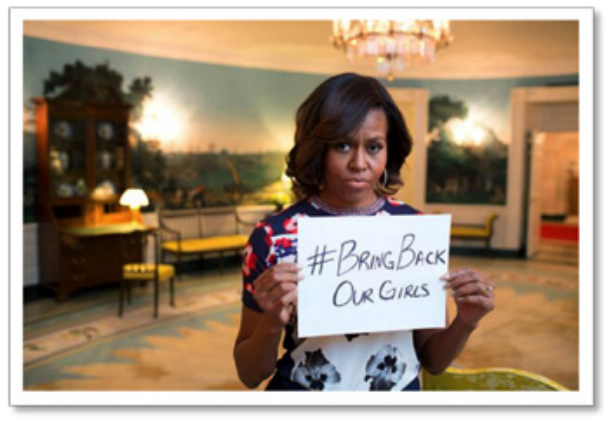


by the brutal eviction of the people that camped at Gezi Park in Istanbul to oppose its planned redevelopment by the government; \#BlackLivesMatter following the 2014 killing of Michael Brown in Ferguson, Missouri, that quickly mutated into the name of an activist organisation and became the driving force at protests that spread across the US; the \#IdleNoMore initiative in Canada; or even the \#CNNfail hashtag that emerged as a criticism of CNN's coverage of the protests during the 2009 presidential election in Iran. On the latter, worth looking at the paper by Nancy Snow (2010) and also Parmalee and Bichard (op.cit.)

Valerie Belair-Gagnon, in her book about the use of Social Media by the BBC (Belair-Gagnon, 2015) provides interesting information about the way hashtags were used by the Corporation (and other news reporters) on occasion of events such as the Mumbai attacks of 2008 or the devastating Haiti earthquake of 2010. For an overview of the role of Social Media's but from the public's side, see Singer (2014).

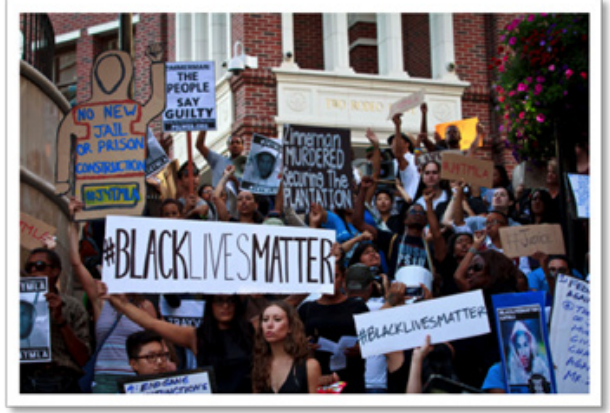

All said, the particular use of hashtags as a conduit for activism (which, in practice, extends to other "instruments" of Social Media) also attracts a fair share of criticism, perhaps best expressed by the concept of "Slactivism." See the article by Jennings-Edquist, "Can you really change the world by sharing a hashtag on social media?" (June 9, 2014; link http://bit.ly/2sEdCol), Michael Flood, "Is 'raising awareness' through social media enough?" (January 28, 2015; link http://bit. ly/2qX0xFb) or Jumoke Balogun's commentary in The Guardian about the Nigerian kidnappings by Boko Haram (Balogun, 2014).

[29] The website run by the Civic Media Project (http://bit.ly/2rMsYad) gives a good account of a multitude of community initiatives (including some of the ones listed above) that have used social networks "capillarity" to spread their message. For a general view on Social Media activism see Jenkins, Ford and Joshua Green (2013). A more specific take on hashtags use in the context of social and political events is offered by Axel Bruns and Jean Burgess (2011).

[30] The suggestion that hashtags primarily support the "spontaneous creation of networks based on shared interests" is also proposed in a paper by Weller, Dröge and Puschmann (2011).

[31] The modern definition of metatext is a text (writing) that reflects on itself (meaning that it describes, discusses or interprets text). The origin of the concept can be traced to medieval scholastics, particularly William of Sherwood who introduced the concept of suppositio materialis or equivalently, the usage of a word instead of itself (Kretzmann, 1966; Fornberg and Hellholm, 1995).

[32] See also http://bit.ly/2s4ShY5.

[33] It must also be stressed that hashtags also provide a means for "transitioning" between the different forms of communication enabled by social networks; for a more complete discussion of how this happens on Twitter, see Bruns and More (ibid., pp. 21).

[34] There are exceptions, though. One such case (among many others) is the \#BlackLivesMatter hashtag that emerged during the 2014 riots in Ferguson; see also note [28] and the references therein. 


\section{MONOGRÁFICO}

[35] Or "social links" as they are also known.

[36] I have already mentioned that collaborative tagging is one of the precursors to our present understanding of hashtags (Golder and Huberman, 2006).

[37] The (increasingly) popular "viral marketing" school of thought, where it's seen as a tool for driving the adoption of products, ideas or behaviors.

[38] See Wikipedia for a definition of density in the context of graph theory; in http://bit. ly/2sgR7se.

[39] Topicality, in a marketing context, refers precisely to products, ideas or behaviors as mentioned before.

[40] Wikipedia provides an overview of the concept of monotonicity; in http://bit.ly/2rBVJI5.

[41] I speak in terms of probability because other things come into the mix, not just the number of connections of a user. See, for example, the earlier references concerning reciprocity (whether a relationship is deemed "informational" or "social") or the issue of topicality mentioned earlier.

[42] Much of the recent push behind the creation of "branded communities" rests on this mechanism. See http://bit.ly/2qXjs2D.

[43] The retweet feature (a button any user could use to forward information of particular interest generated by a third party to all of his/her followers) was introduced in late 2009. See http://bit.ly/2r32ST9.

[44] Although I can think of Guy Kawasaki as an exception that confirms such rule. See https:// twitter.com/GuyKawasaki.

[45] The notion of cohesiveness finds its origin in the sociological concept of clique introduced in a paper by R. Duncan Luce and Albert Perry published in 1949.

[46] The authors adopt one of the possible definitions of a community in the Merriam-Webster online dictionary: "a group of people with a common characteristic or interest living together within a larger society." For a broader perspective, see White (2009) and also the classic book by Wasserman and Faust (1994). The tendency for similar people group together is known as homophily (http://bit.ly/2rCa2MV).

[47] If $V$ denotes a vertex (or node) and $E$ an edge, given a graph $G(V, E)$ a subgraph $S$ of $G$ is such that $V(S) \mid V(G)$ and $E(S) \mid E(G)$ meaning: all nodes in $S$ are also in $G$ and all edges in $S$ are also in $\mathrm{G}$.

[48] See Wikipedia for a simple explanation of distance in graphs; in http://bit.ly/2cWqsuL.

[49] A group (community) is considered local if it is definable over subgraphs only induced by the group. Therefore, it neglects the network outside the group. This is not equivalent to separability (implying that group members have more contacts inside than outside the group) which is one of the four "standard attributes" of cohesiveness; see Wasserman and Faust (op.cit.), Chap. 7. 
[50] Once again, I resort to Wikipedia for an overview of the concept of degree; see http://bit. ly/2r6qh0U. In social networks such as Twitter, where edges are directed, nodes have an in-bound degree (number of followees a user has) and also an out-bound degree (number of users being followed by that user). See also the collateral concept of reciprocity.

[51] Assortativity was introduced by Mark Newman (2002) and developed further in Newman and Park (2003).

[52] For example, see Hai-Bo Hu and Xiao-Fang Wang (2009); for a case focusing on Twitter, see Zhou, Bandari, Kong, Quian and Roychowdhury (2010).

[53] Since then, see http://for.tn/22Lz8Em and http://bit.ly/1nPWI2E.

[54] For example, the political and social events I've quoted at length in Note 28.

[55] See Shalizi and Thomas (2011). That assortativity might depend on the trait being measured is reflected in the work by Bliss, Kloumann, Harris, Danforth and Dodds (2012).

[56] A proper in-depth analysis of the semiotics (and linguistics) of the hashtag clearly exceeds the boundaries of this paper. In passing, I would note Propp's view that "[an] action cannot be defined apart from its place in the course of narration. The meaning which a given function has in the course of action must be considered." (Propp, 1968, underline mine.)

[57] I postulate them as hypotheses based on existing findings (some of that work has been quoted above) but they need to be properly validated through ad-hoc research.

[58] The question of what is "enough" has no simple (or immediate) answer; we only stipulate that there is likely a threshold above which the balance tips. Of course I'm talking here about reach in media parlance : "the number of different persons or homes exposed to a specific media vehicle or schedule at least once." See Jack Scissors and Roger Baron, Advertising Media Planning, McGraw-Hill (2002).

[59] By content I mean the combination of message and creative cues of an advert.

[60] Note that hashtags, despite their popularity, are not supported by all social networking platforms.

[61] Note I'm not suggesting that amplification would be necessarily positive; in fact, it could well turn to be the opposite and there are many examples to prove it : besides the \#McDStories gaffe I already spoke about and another mishap by McDonald's, I could also mention MasterCard's \#Priceless Surprises hashtag hijack, Starbuck's \#RaceTogether failure, the reactions to Bud Light's \#UpFor Whatever hashtag, the \#susanalbumparty or \#MyNYPD epic PR disasters. This is just a snapshot of how things could go wrong very easily in social media.

[62] Despite society becoming so much more digitally-aware, there are huge (data and knowledge) gaps in relation to our ability to link what happens within the digital realm and the behavior outside it. In fact, many assumptions are still being made (sometimes pontificated as hard-facts) as to how (and which) digital and non-digital channels motivate consumers through the different stages in their journey.

[63] For a perspective on audience profiling and precision targeting, those interested can read an article I posted months ago on LinkedIn Pulse (see http://bit.ly/2nw5Zx7). Some further thoughts, also published on LinkedIn Pulse, can be found here http://bit.ly/2sE11Bl). 
MONOGRÁFICO

[64] For a discussion, see Varese and Castagno (2011).

[65] Let's not forget the first-generation iPhone was launched in June 2007 and that HTC introduced in the US the first handset based on the Android software, the T-Mobile G1 (also known as HTC Dream) in October 2008.

[66] See Les Orchard's blog entry about using tags as a sort-of sticky note on Twitter. See http:// bit.ly/2r6yrXa.

[67] Reproducing a chart originally published in the online site Statista. See http://bit. ly/2sU5bV9.

[68] Such news, however, seemingly keeps coming as a surprise of some marketers. Perhaps that's due to a basic confusion : "brand love" is mostly a reflection of high levels of category involvement (by hyper-involved consumers) rather than being an attribute of the brands themselves. In other words, the passion consumers' show for certain categories (a car nut or a fashionista, say) maps back to the brand(s) they are familiar with or have purchased in the past within those categories.

[69] Formats where there seems to be less of a controversy about the viewability of advertising by consumers. See also http://bit.ly/1N1JVjo.

[70] Hashtags are used by every major social networking and micro-blogging service : that means Twitter of course, but also Instagram, Pinterest, Facebook, Google+, YouTube, Tumblr, Flickr, Orkut, Diaspora and Tout, for example. LinkedIn is the notable exception in this list, although in early 2015 it added a 3-keyword tagging facility for posts. There are differences between platforms in the implementation of hashtags, however.

[71] For example, thinking of Twitter an "adopter" would be a user that tweets a p\#.

[72] Consumption, after all, is a value exchange.

[73] See, for example, the article by Jack Marshall on the Wall Street Journal, quoting a research piece by Forrester (Marshall, 2014). Things haven't changed much since then.

\section{References}

When available, freely downloadable versions of the referenced material (whether provided by the authors or journal publishers) is provided.

Acar, A. and Muraki, Y. (2011), “Twitter for crisis communication: lessons learned from Japan's tsunami disaster," International Journal of Web Based Communities, vol. 7, no. 3, 392-402. Link http://bit.ly/2qXCiH9.

Balogun, J. "Dear world, your hashtags won't \#BringBack0urGirls," The Guardian (May 9, 2014). Link http://bit.ly/1nq5e5F. 
Hashtags 2.0 - An Annotated History of the Hashtag and a Window to its Future | 50

MONOGRÁFICO

Belair-Gagnon, V. (2015), Social Media at BBC News: The Re-Making of Crisis Reporting, London: Routledge, Chapter 2.

Bliss, C., Kloumann, I., Harris, K., Danforth, C. and Dodds, P. (2012), "Twitter reciprocal reply networks exhibit assortativity with respect to happiness," Journal of Computational Science, vol. 3. Link http://bit. ly/2rMp3u2.

Bough, B. B. and Agresta, S. (2001), Perspectives on Social Media Marketing, Cengage Learning, J Miletsky (series Ed.), 1st. edition, 188.

Brown, C. (2012), “\#Memstorm: Twitter as a Community Driven Breaking News Reporting Tool," \#ISOJ: The International Symposium on Online Journalism. See http://bit.ly/2r2NR3B.

Bruns, A. and Burgess, J. (2011), "The use of Twitter hashtags in the formation of ad hoc publics," Proceedings of the 6th. European Consortium for Political Research (ECPR) General Conference, Reykjavik (2011). Link http://bit.ly/10gC5mZ.

Bruns, A. and Stieglitz, S. (2012), "Quantitative approaches to comparing communication patterns on Twitter," Journal of Technology in Human Services, vol. 30, 160-185. See http://bit.ly/2s4ZSpw.

Bruns, A. and Moe, H. (2013), "Structural layers of communication on Twitter." In Katrin Weller, Axel Bruns, Jean Burgess, Merja Mahrt and Cornelius Puschmann (Eds.), Twitter and Society, Bern: Peter Lang Verlagsgruppe. DOI: 10.3726/9781-4539-1170-9. Link http://bit.ly/2r6wudv.

Calore, M. "California Fire Followers Set Twitter Ablaze" in the Wired.com blog (0ctober 22, 2007).

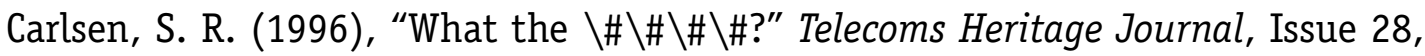
52-53

Cheng, J., Romero, D., Meeder, B. and Klienberg, J. (2011), “Predicting Reciprocity in Social Networks," Proceedings of the 3rd IEEE Conference on Social Computing (SocialCom), Boston. Link http://bit.ly/2sTR0za.

Cho, C. "For More Advertisers, The Medium is the Text Message," The Wall Street Journal (August 2, 2004). Link http://on.wsj.com/2sgSeYW.

Christensen, W. and Suess, W. (1978), "Hobbyist Computerized Bulletin Board," BYTE Magazine, vol. 3, no. 11 (November), 150-157.

Douai, A. (2013), "Seeds of change in Tahrir Square and beyond: People power or technological convergence?" American Communication Journal, vol. 15, no.1, 24-33. 


\section{MONOGRÁFICO}

Fornberg, T. and Hellholm, N. (1995), Texts and Contexts: Biblical Texts in Their Textual and Situational Contexts - Essays in Honor of Lars Hartman, 0slo: Scandinavian University Press.

Golder, S. and Huberman, B. (2006), “Usage patterns of collaborative tagging systems," Journal of Information Science, vol. 32, no. 2. Link http://bit. $\mathrm{ly} / 2 \mathrm{~s} 58 \mathrm{e} 0 \mathrm{o}$.

Hoff, T. "The Architecture Twitter Uses To Deal With 150M Active Users, 300K QPS, A 22 MB/S Firehose, And Send Tweets In Under 5 Seconds" (July 8, 2013). See http://bit.ly/1hrDQfb.

Howard, P. and Hussain, M. (2011), "Digital Media and the Arab Spring," Journal of Democracy, vol. 22, no. 3: 35-48.

Howard, P. and Hussain, M. (2013), Democracy's Fourth Wave? Digital Media and the Arab Spring, Oxford Studies in Digital Politics, New York: Oxford University Press. DOI: 10.1093/acprof:oso/9780199936953.001.0001

Howard, T. (2010), Design to thrive: Creating social networks and online communities that last, Burlington: Morgan Kaufmann Publishers.

$\mathrm{Hu}, \mathrm{B}$. and Wang, X. (2009), "Dissasortative mixing in online social networks," Europhysics Letters Association, vol. 86, no. 1. See http://bit.ly/2rMxdlX.

Huston, K. (2013), Shady Characters: The Secret Life of Punctuation, Symbols and Other Typographical Marks, New York: W.W. Norton \& Company.

Jenkins, H., Ford, S. and Green, J. (2013), Spreadable Media: Creating Value and Meaning in a Networked Culture, New York: New York University Press.

Koten, J., "Behind Two Symbols on a Telephone Keypad," The Wall Street Journal (March 28, 1994).

Kretzmann, N. (1966), William of Sherwood: Introduction to Logic, University of Minnesota Press.

Lim, M. (2012), "Clicks, cabs, and coffee houses: social media and oppositional movements in Egypt," Journal of Communication, vol. 62, no. 2, 231-248.

Lim, K. H. and Datta, A. (2013), "A Topological Approach for Detecting Twitter Communities with Common Interests," in Martin Atzmuller, Alvin Chin, Denis Helic and Andreas Hotho (Eds.), Ubiquitous Social Media Analysis, Lecture Notes in Artificial Intelligence 8239, Heidelberg: Springer, 23-43. See http://bit.ly/2r605do. Luce, R. D. and Perry, A. (1949), "A Method of Matrix Analysis of Group Structure," Psychometrica, vol. 14, no. 1. See http://bit.ly/2sTHNHd. 
Malik, 0. "Silicon Valley is all Twttr" (Jul 15, 2006). Link http://bit.ly/2sErQFp. Marlow, C., Naaman, M., Boyd, D. and Davis, M. (2006), “HT06, tagging paper, taxonomy, Flickr, academic article, to read," Proceedings of the 17th ACM Conference on Hypertext and hypermedia (HYPERTEXT '06), Odense. See http://bit.ly/2sgAjRQ. Marshall, J. "Brands Are Wasting Money on Facebook and Twitter, Forrester Says," The Wall Street Journal (November 17, 2014). Link http://on.wsj.com/2rYSk6E. Mullman, J. "Land Rover Taps Twitter as Campaign Cornerstone," AdAge (April 20, 2009). Link http://bit.ly/2qX6FgR.

Muller-Prove, M. (2008), "Modell und Anwendungperspektive des Social Tagging," Chapter 2 of Birgit Gaiser, Thorsten Hampel and Stephanie Panke (Eds.), Good Tags - Bad tags. Social Tagging in der Wissensorganisation. Waxmann: Berlin. Myers, S., Sharma, A., Gupta, P. and Lin, J. (2014), “Information Network or Social Network? The Structure of the Twitter Follow Graph," Proceedings of the 23rd ACM International Conference on World Wide Web (WWW '14), New York. Link http://bit.ly/2r2FqFC.

Newman, M. (2002), “Assortative Mixing in Networks," Physical Review Letters, vol. 89, no. 20. Link http://bit.ly/2rVVUyq.

Newman, M. and Park, J. (2003), "Why social networks are different from other types of networks," Physical Review Letters E, vol. 68, no. 3. See http://bit. ly/2rW952G.

Nideffer, R. (1995), Bodies, No-bodies and Anti-bodies at War: Operation Desert Storm and the Politics of the Real. Unpublished PhD Thesis, UCSB: Chapter 5.

0strow, A. "Sponsored Hashtags: A Brand Risk Worth Taking?" Mashable (April 21, 2009). See http://on.mash.to/2sEAbcz.

Papacharissi, Z. and de Fatima Oliveira, M. (2012), "Affective News and Networked Publics: The Rhythms of News Storytelling on \#Egypt" Journal of Communication, vol. 62, no. 2, 266-282.

Parmalee, J. and Bichard, S. (2012), Politics and the Twitter revolution: How tweets influence the relationship between political leaders and the public, Lanham: Lexington Books. D0I: 10.1002/polq.12021.

Propp, V. (1968), Morphology of the Folktale, Austin: University of Texas Press, 2nd Ed. Richardson, M. and Domingos, P. (2002), "Mining Knowledge-Sharing Sites for Viral Marketing," Proceedings of the 8th. ACM International Conference on Knowledge Discovery and Data Mining (KDDM), Edmonton. Link http://bit.ly/2s5qFSq. 


\section{MONOGRÁFICO}

Rheingold, H. (2000), The Virtual Community: Homesteading on the Electronic Frontier, Cambridge: The MIT Press, 2nd. edition.

Rzeszotarski, J., Spiro, E., Matias, J., Monroy-Hernández, A. and Morris, M. (2014), "Is anyone out there? Unpacking Q\&A hashtags on Twitter," ACM (Association for Computer Machinery) CHI Conference on Human Factors in Computing Systems, Toronto. Link http://bit.ly/2qX7nL3.

Schifanella, R., Barrat, A., Cattuto, C., Markines, B. and Menczer, F. (2010), “Folks in Folksonomies: Social Link Prediction from Shared Metadata," 3rd ACM International Conference on Web Search and Data Mining (WSDM), New York. Link http://bit.ly/2r60Drz.

Shalizi, C. and Thomas, A. (2011), "Homophily and Contagion Are Generically Confounded in Observational Social Network Studies," Sociological Methods and Research, vol. 40, no. 2. See http://bit.ly/2sgDp8L.

Singel, R. "In Disasters, Everyone, Not Just Bloggers, Should Use Twitter" (October 24, 2007). Link http://bit.ly/2qXkxHJ.

Singer, J. (2014), "User-generated visibility: Secondary gatekeeping in a shared media space," New Media and Society, vol. 16, no. 1, 55-73.

Snow, N. (2010), "What's that chirping I hear? From the CNN effect to the Twitter effect." In Yahya Kamalipour (Ed.), Media, power, and politics in the digital age: The 2009 presidential election uprising in Iran, Lanham: Rowman \& Littlefield, 97-104. Link http://bit.ly/2sEphDv.

Starbird, K. and Palen, L. (2010), "Pass it on? Retweeting in mass emergency," 7th. International ISCRAM Conference, Seattle. Link http://bit.ly/2rBXIMo.

Tsur, 0. and Rappoport, A. "What's in a Hashtag? Content based Prediction of the Spread of Ideas in Microblogging Communities," 5th ACM International Conference on Web Search and Data Mining (WSDM), Seattle (2012). See http://bit.ly/22qdXrf. Varese,G. and Castagno, S. (2011), "Building Collective Tag Intelligence through Folksonomy Coordination," in Nick Bessis and Fatos Xhafa (Eds.), Next Generation Data Technologies for Collective Computational Intelligence, Berlin: Spinger-Verlag.

Wasserman, S. and Faust, S. (1994), Social Network Analysis: Methods and Applications, Cambridge: Cambridge University Press.

Weller, K., Dröge, E. and Puschmann, C. (2011), "Citation analysis in Twitter: Approaches for defining and measuring information flows within tweets 
Hashtags 2.0 - An Annotated History of the Hashtag and a Window to its Future | 54

during scientific conferences," \# MSM2011 - First Making Sense of Microposts Workshop, Co-located with 8th. Extended Semantic Web Conference, Crete. Link http://bit.ly/2r6LNDb.

White, D. (2009), "Innovation in the Context of Networks, Hierarchies and Cohesion," in David Lane, Denise Pumain, Sander van der Leew and Geoffrey West (Eds.), Complexity Perspectives in Innovation and Social Change, New York: Springer, 153-196. Link http://bit.ly/2sgV3sV.

Yang, L., Sun, T., Zhang, M. and Mei, Q. (2012), “We know what@ you\# tag: Does the dual role affect hashtag adoption?" Proceedings of the ACM 21st. International Conference on World Wide Web, New York, 261-270. See http:// bit.ly/2rBPcNt.

Zappavigna, M. (2012), Discourse of Twitter and Social Media: How We Use Language to Create Affiliation on the Web, London: Continuum.

Zhou, Z., Bandari, R., Kong, J., Quian, H. and Roychowdhury, V. (2010), “Information Resonance on Twitter: Watching Iran," 1st ACM Workshop on Social Media Analytics (SOMA '10), Washington. Link http://stanford.io/2rMpg06. 